\title{
PERCEPÇÃO AMBIENTAL COMO AVALIAÇÃO DA EFETIVIDADE DA APA DOS PIRENEUS - GOIÁS
}

\author{
Environmental Perception as Effective Assessment of APA Pirineus - Goiás
}

\author{
Dayan de Loyola Ramos Garcia ${ }^{1}$, Katia Kopp ${ }^{2}$, Emiliano Lôbo de Godoi ${ }^{3}$
}

Recebido em 14 de março de 2015; recebido para revisão em 08 de junho de 2015; aceito em 10 de julho de 2015; disponivel on-line em 01 de agosto de 2015.

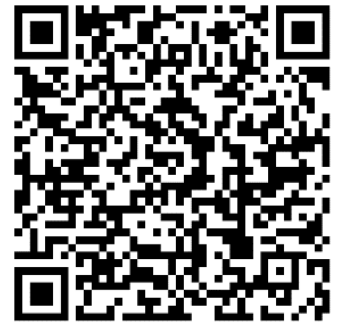

PALAVRAS CHAVE:

Unidade de conservação;

Recursos naturais;

Avaliação da efetividade;

Percepção ambiental.

\section{KEYWORDS:}

Protected area;

Natural resources;

Evaluation of the

effectiveness;

Environmental perception.
RESUMO: No Brasil as chamadas Unidades de Conservação (UCs), são áreas com limites territoriais estabelecidos por Lei, abrangendo recursos ambientais destinados à conservação. Partindo da preocupação com a efetividade das unidades de conversação devido a não participação da população local na gestão, nesse trabalho realizou-se um levantamento do conhecimento dos residentes de uma UC acerca dos objetivos desta e dos usos da biodiversidade e dos recursos hídricos. A UC estudada foi a Área de Proteção Ambiental dos Pireneus na intersecção dos Municípios goianos de Pirenópolis, Corumbá de Goiás e Cocalzinho de Goiás. Para coleta dos dados foram utilizados questionários, que posteriormente foram categorizados e estatisticamente analisados. Verificou-se que poucos entrevistados souberam ao certo as funcionalidades da APA dos Pireneus e que existe muita confusão conceitual por parte da população residente na APA. [Principal Contribuição] Constatou-se a importância da divulgação da APA pelo poder público e a necessidade de integração da população local no processo de gestão da unidade.

ABSTRACT: In Brazil the Protected Areas calls (PAs), are areas with boundaries established by law, including environmental resources for conservation. Starting from the concern about the effectiveness of protected areas due to non participation of local people in management, in this work we carried out a survey of the knowledge of residents of a UC about the objectives of this and about the uses of biodiversity and water resources. The PA studied was the Environmental Protection Area of the Pirineus at the intersection of Municipalities of Goiás, Pirenópolis, Corumbá de Goiás and Cocalzinho of Goiás. Questionnaires were used to collect data, which were then categorized and analyzed statistically. It was found that few respondents knew what were the functions of the APA Pirineus and there is much conceptual confusion on the part of the resident population in the APA. [Main Contribution] It was noted the importance of disseminating the APA by the government and the need for integration of local people in protected area management process.

* Contato com os autores:

${ }^{1}$ e-mail : dayanengamb@gmail.com ( D. L. R. Garcia )

Engenheiro Ambiental e Sanitarista, Assessor Técnico na Incubadora Social da UFG, Universidade Federal de Goiás.

2e-mail : kakopp@gmail.com (K. Kopp)

Bióloga, Professora do Curso de Engenharia Ambiental e Sanitária e do Programa de Pós-Graduação em Engenharia Ambiental e Sanitária (PPGEAS), Escola de Engenharia Civil, Universidade Federal de Goiás.

${ }^{3}$ e-mail : emiliano@ufg.br ( E. L. Godoi )

Engenheiro Agrônomo, Professor do Curso de Engenharia Ambiental e Sanitária, Escola de Engenharia Civil, Universidade Federal de Goiás.

1. INTRODUÇÃO

As Unidades de Conservação (UCs) se constituem de espaços territoriais com limites definidos, juntamente com recursos ambientais, incluindo as águas jurisdicionais, com 
características ambientais relevantes à conservação, sob regime de administração que visa garantir a proteção de tais recursos (Lei № 9.885 de 18 de Julho de 2000).

Buscando uma efetiva atuação da Política Nacional do Meio Ambiente, que até o final do séc. XX não agira de maneira integrada nacionalmente em relação às UCs, e a fim de sistematizar os grupos e as categorias de Unidades de Conservação, a Lei № 9.885 de 18 de Julho de 2000, regulamentada pelo Decreto № 4.340 de 22 de Agosto de 2002, instituiu diretrizes para a implementação do Sistema Nacional de Unidades de Conservação (SNUC). Dentre essas diretrizes está aquela que dispõe que o processo de criação e a gestão das unidades de conservação sejam feitos de forma integrada com as políticas de administração das terras e águas circundantes, considerando as condições e necessidades sociais e econômicas locais (BRASIL, 2000).

Para reforçar a diretriz instituída pelo SNUC, foi promulgada a Lei № 14.247 de 29 de Julho de 2002, que trata da criação do Sistema Estadual de Unidades de Conservação do Estado de Goiás (SEUC). Atualmente, Goiás sedia 21 Unidades de Conservação Estaduais, sendo, 11 de Proteção Integral e 10 de Uso Sustentável (SEMARH, 2013). Dentre as unidades de conservação de uso sustentável, se enquadra a Área de Proteção Ambiental (APA). Segundo o SNUC, a APA é uma área em geral extensa, com um certo grau de ocupação humana, dotada de atributos abióticos, bióticos, estéticos ou culturais especialmente importantes para a qualidade de vida e o bem-estar das populações humanas, e tem como objetivos básicos proteger a diversidade biológica, disciplinar o processo de ocupação e assegurar a sustentabilidade do uso dos recursos naturais.

No Estado de Goiás existem oito APAs dentre as quais, a APA dos Pireneus, que foi criada pelo Decreto № 5.174 de 17 de Fevereiro de 2000. De acordo com esse Decreto, esta APA possui como propósitos básicos a proteção da região serrana e o entorno do Parque Estadual dos Pireneus, disciplinar o turismo ecológico e fomentar a educação ambiental.
No entanto, apesar do número relativamente alto de APAs e outras unidades de conservação no Estado de Goiás, e mesmo com a legislação sendo proposta em uma sistemática bem elaborada e integrada, a eficácia destas unidades está sendo colocada à prova constantemente. A ineficácia de várias UC's muitas vezes está ligada à falta de participação da sociedade civil na gestão da unidade, à percepção ambiental da população controversa à proteção, à deficiência na difusão da informação do governo para o público e a própria ausência da administração pública.

Partindo do pressuposto de que, muitas unidades de conservação não são efetivamente implantadas, e nem funcionam adequadamente, devido à ausência de participação da população local ou de mecanismos necessários a sua gestão e a outros empecilhos legais ou institucionais, e que a falta de cumprimento dos objetivos que foram estabelecidos na lei da unidade onera o Estado, não atinge a efetividade esperada e, por conseguinte, não protege o que foi decretado em ser protegido, esse estudo objetivou analisar a percepção ambiental da população residente em uma unidade de conservação acerca da funcionalidade dessa área a fim de gerar informações uteis a sua gestão.

\section{OBJETIVO}

O presente estudo objetivou relacionar as funcionalidades da Área de Proteção Ambiental dos Pireneus com o entendimento acerca das questões ambientais dos moradores residentes na área desta unidade de conservação.

\section{METODOLOGIA}

\subsection{COLETA DE DADOS}

Este estudo teve como população alvo os moradores do Município de Pirenópolis, abrangendo as zonas rural e urbana. A população total do Município levantada em 2010 foi de 23.006 habitantes (IBGE, 2010).

Para coletar os dados de percepção ambiental dos habitantes da região sobre os objetivos da APA dos Pireneus foi utilizado um questionário com questões que abordavam: (1) a identificação dos indivíduos; (2) o conhecimento sobre a APA dos Pireneus; (3) e a conservação da 
biodiversidade e dos recursos hídricos. Para se estabelecer o questionário aplicado, primeiramente foram feitos um questionário-teste e uma aplicação-teste. Mediante a análise da aplicação-teste, o questionário efetivo contemplou 23 questões que abordavam os três aspectos acima citadas.

A aplicação dos questionários foi executada abordando-se aleatoriamente as pessoas (maiores de 18 anos) nas portas de suas residências ou em seus locais de trabalho. Os questionários foram apresentados aos entrevistados após os mesmos receberem o Termo de Consentimento Livre e Esclarecido (TCLE), conforme exigido pelo Comitê de Ética da Universidade Federal de Goiás. O TCLE continha as informações sobre a pesquisa e possibilitava que o possível entrevistado aceitasse ou não responder o questionário. Após o aceite, aquelas pessoas que não se sentiam seguras a responder o questionário sozinhas eram auxiliadas na leitura das perguntas pelo próprio entrevistador. Em todos os casos em que foi solicitada ajuda para responder ao questionário, sempre o mesmo entrevistador prestou o auxílio para evitar problemas relacionados a interpretações distintas das questões constantes nesse instrumento de coleta. O julgamento das respostas foi feito com base em critérios pós coleta de dados, na etapa de análises estatísticas.

Para a determinação do tamanho da amostra (ou seja, do número de questionários que deveria ser aplicado à população), foi utilizado o método proposto por PALMA (2005). Com base na população-alvo total do município (23.006 habitantes), calculou-se como número mínimo representativo de questionários a serem aplicados o valor de 99 questionários. A partir do final de Abril de 2013 e durante Maio de 2013 os questionários foram aplicados, totalizando ao final deste período 100 questionários aplicados.

Das 100 pessoas amostradas, todas residiam em Pirenópolis; 59 pessoas pertenciam ao sexo masculino, enquanto 41 pessoas pertenciam ao sexo feminino; 82 pessoas residiam na área urbana e 18 pessoas residiam na área rural; em relação a escolaridade amostrou-se 12 pessoas com Ensino Fundamental Incompleto, 13 pessoas com Ensino Fundamental Completo, 16 pessoas com Ensino Médio Incompleto, 29 pessoas com Ensino Médio Completo, 12 pessoas com Ensino Superior Incompleto, 16 pessoas com Ensino Superior Completo e duas pessoas analfabetas. Já em relação à atividade ocupacional, 37 pessoas atuavam na área comercial, 4 pessoas trabalhavam com agricultura, 28 pessoas atuavam como profissional liberal, 3 pessoas estavam desempregadas, 3 pessoas já se encontravam aposentadas, 7 pessoas atuavam no serviço público e 3 pessoas desempenhavam outras atividades.

\subsection{ANÁLISES ESTATÍSTICAS}

As questões abordadas no questionário foram tabuladas e transformadas em uma matriz básica de dados utilizando uma planilha eletrônica. Posteriormente foram confeccionadas tabelas de contingência relacionando as variáveis socioeconômicas e culturais da população amostrada com as variáveis de utilização da biodiversidade e dos recursos. Como os dados não apresentaram distribuição normal foram utilizados testes não paramétricos para a análise dos mesmos (teste Qui-Quadrado $\left[\mathrm{X}^{2}\right]$ e teste G). Para a elaboração das tabelas de contingência e aplicação dos testes se utilizou o software BioeStat 5.0 (2008).

Em algumas questões do questionário aplicado aos entrevistados foi necessário realizar a confirmação de dados ou a categorização das respostas antes de se proceder às análises estatísticas. Dessa forma, na questão que abordava o conhecimento dos entrevistados sobre espécies ameaçadas de extinção, foi realizada a confirmação das espécies respondidas, considerando como corretas apenas aquelas que constam no "Livro Vermelho da Fauna Brasileira Ameaçada de Extinção" (MMA, 2008).

$\mathrm{Na}$ questão sobre o conhecimento e a definição de APA, foram estipuladas cinco categorias, sendo:

- categoria 1 - "Correta": foram enquadradas as respostas consideradas corretas, quando os entrevistados definiram duas ou mais funções 
corretas da APA segundo a legislação que a instituiu (Decreto № 5.174, de 17 de Fevereiro de 2000);

- categoria 2 - "Parcialmente Correta": foram enquadradas as respostas consideradas parcialmente corretas, quando os entrevistados elencaram somente uma única função da APA;

- categoria 3 - "Errada": foram contabilizadas as respostas erradas fque não continham nenhuma função correta da APAt;

- categoria 4 - "Respondeu sim, mas não definiu": foram enquadradas as respostas de participantes que alegaram conhecer a APA, mas não descreveram nada a respeito de sua função;

- categoria 5 - "Não conhece a APA": foi enumerado o número de pessoas que declararam não conhecer a APA.

\section{RESULTADOS E DISCUSSÃO}

\subsection{CONHECIMENTOS DA POPULAÇÃO SOBRE A APA DOS PIRENEUS}

Das pessoas entrevistadas, 49 pessoas (49\%) afirmaram que sabiam o que é a APA dos Pireneus, mas apenas 26 pessoas (26\%) responderam o campo "para que ela serve", sendo que destas, somente duas pessoas conseguiram definir corretamente o que era APA. Depois de categorizar as respostas, como descrito nos procedimentos metodológicos, foi contabilizado o número de respostas de cada categoria conforme pode ser verificado na Figura 1.

$\mathrm{Na}$ aplicação dos questionários, notou-se que muitas pessoas que alegavam conhecer a APA dos Pireneus confundiam esta unidade com o Parque Estadual dos Pireneus, pois se referiam à APA utilizando o pronome "lá", não sabendo que mesmo dentro da cidade estavam dentro da unidade de conservação. Este fato é comprovado por definições da função da APA respondidas pelos entrevistados, como por exemplo: “... Para visitar e moradia para os animais" e "... Para festas religiosas".

Oliveira (2011) afirma em seu estudo na APA do Puraquequara - AM, que 51,3\% dos moradores entrevistados não sabiam o que é uma APA, enquanto $48,6 \%$ alegaram saber, mas foi identificado que os entrevistados não possuem ideia clara do que possa ser e qual sua funcionalidade, fazendo transparecer a falta de esclarecimento e informação sobre este tipo de unidade de conservação, onde poucos percebem que estão em uma área com o propósito de uso dos recursos naturais de forma planejada. Isso também foi observado no presente estudo demonstrando que muitas pessoas ainda não possuem uma ideia clara do que é a APA dos Pirineus e dos seus objetivos. Evidencia-se que existe uma confusão conceitual entre a APA e o Parque Estadual dos Pirineus.

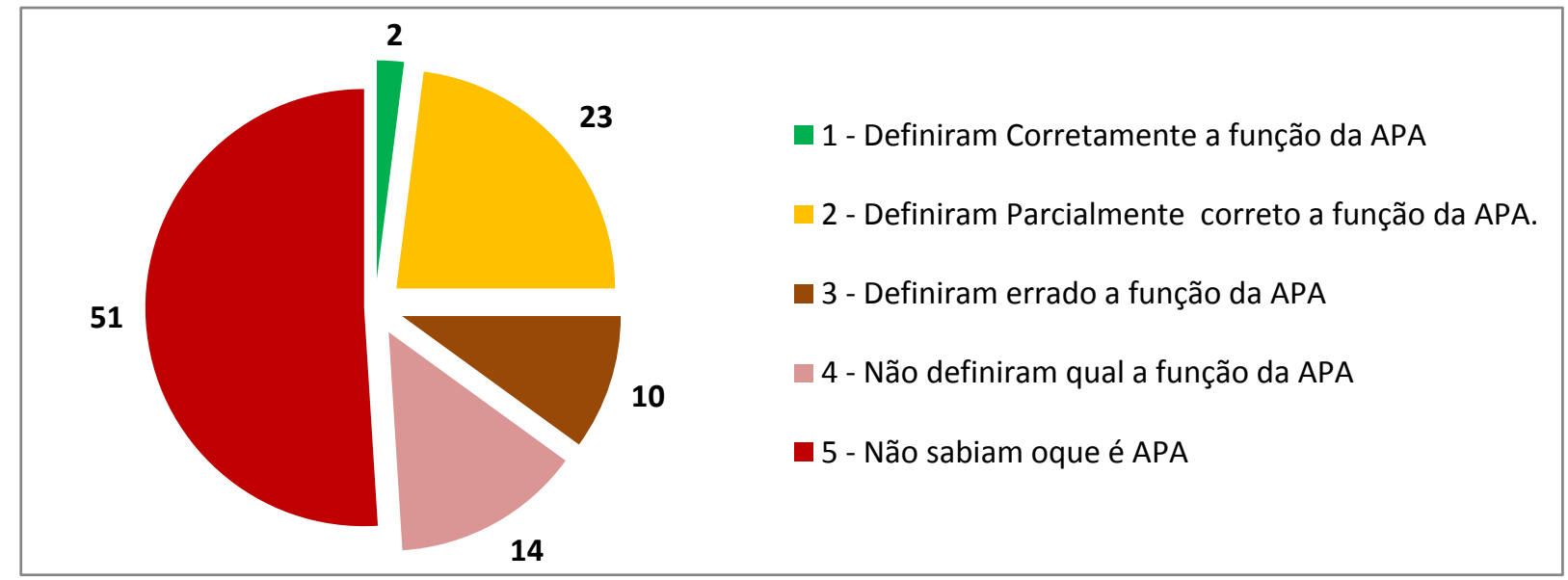

FIGURA 1: Categorização das respostas obtidas por meio de questionário aplicado a uma amostra da população rural e urbana do Município de Pirenópolis, Goiás sobre o conhecimento acerca do que é a APA dos Pirineus e qual a função dessa Unidade de Conservação. 
Em seu estudo, Castro (2007) aponta por meio dos indicadores obtidos relacionados ao parâmetro "Comunicação e Informação" na avaliação do Parque Estadual da Serra do Brigadeiro, que, apesar da quantidade de informações existentes sobre a unidade, é necessário o desenvolvimento de mecanismos mais eficazes na ampliação das formas e locais de acesso a essas informações. No presente estudo, mesmo sendo a APA dos Pireneus regulamentada pelo Decreto № 5.174, de Fevereiro de 2000, que dispõe sobre o funcionamento e seus limites, estas informações não atingem a maioria da população, fato comprovado pelo baixo número de pessoas que realmente definiram as funções da APA (duas pessoas).

\subsection{PERCEPÇÕES DA POPULAÇO EM RELAÇÃO AOS USOS DA BIODIVERSIDADE E DOS RECURSOS HÍDRICOS}

Para as relações socioeconômicas e ambientais estabelecidas, aplicaram-se os testes adotados (teste Qui-Quadrado $\left[\mathrm{X}^{2}\right]$ e teste $\mathrm{G}$ ) e obtiveram-se os resultados apresentados na Tabela 1.

TABELA 1: Relação das variáveis utilizadas para análise da percepção ambiental dos moradores de Pirenópolis em relação aos recursos hídricos e à biodiversidade, juntamente com o valor do teste realizado ( $\chi^{2}$ ou $\mathrm{G}$ ) e o valor de $p$ obtido.

\begin{tabular}{|c|c|c|c|}
\hline Relação entre as variáveis & $\mathbf{X}^{2}$ & G & p-valor \\
\hline Escolaridade x "O que é APA?" & 3,205 & - & 0,668 \\
\hline Participação ambiental em grupos organizados x "O que é APA?" & 8,954 & - & 0,006 \\
\hline Escolaridade x "Qual a função da APA?" & - & 25,654 & 0,200 \\
\hline Participação ambiental em grupos organizados x "Qual a função da APA?" & - & 3,712 & 0,356 \\
\hline $\begin{array}{l}\text { Zona x Pessoas que utilizam plantas e/ou animais para alimentação ou } \\
\text { medicamento. }\end{array}$ & 5,825 & - & 0,033 \\
\hline $\begin{array}{l}\text { Idade x Pessoas que utilizam plantas e/ou animais para alimentação ou } \\
\text { medicamento. }\end{array}$ & - & 7,754 & 0,202 \\
\hline $\begin{array}{l}\text { Zona x "APA criada para proteger animais e plantas importantes ao bioma } \\
\text { cerrado?" }\end{array}$ & - & 0,656 & 0,737 \\
\hline $\begin{array}{l}\text { Participação ambiental em grupos organizados x "APA foi criada para proteger } \\
\text { animais e plantas importantes ao bioma Cerrado?" }\end{array}$ & - & 0,065 & 0,969 \\
\hline Zona x "Deve-se proibir ou limitar a extração de plantas na região da APA?" & - & 4,797 & 0,151 \\
\hline Idade x "Deve-se proibir ou limitar a extração de plantas na região da APA?" & - & 16,803 & 0,011 \\
\hline Zona x "Deve-se proibir ou limitar a caça aos animais silvestres na região da APA?" & - & 0,087 & 0,727 \\
\hline $\begin{array}{l}\text { Idade } x \text { "Deve-se proibir ou limitar a caça aos animais silvestres na região da } \\
\text { APA?" }\end{array}$ & - & 4,750 & 0,595 \\
\hline Zona x № de espécies em extinção conhecidas & - & 3,039 & 0,488 \\
\hline Idade x № de espécies em extinção conhecidas & - & 14,916 & 0,828 \\
\hline
\end{tabular}


TABELA 1: Relação das variáveis utilizadas para análise da percepção ambiental dos moradores de Pirenópolis em relação aos recursos hídricos e à biodiversidade, juntamente com o valor do teste realizado ( $\chi^{2}$ ou $\mathrm{G}$ ) e o valor de $p$ obtido. (Continuação).

\begin{tabular}{|c|c|c|c|}
\hline Relação entre as variáveis & $\mathrm{X}^{2}$ & G & p-valor \\
\hline Zona x "APA mantem a qualidade da água da região?" & - & 2,395 & 0,506 \\
\hline $\begin{array}{l}\text { Zona } x \text { "No limite da APA, indústrias e criatórios de animais deveriam tratar seus } \\
\text { esgotos antes de lança-los nos rios?" }\end{array}$ & - & 1,015 & 0,958 \\
\hline $\begin{array}{l}\text { Fonte de Renda x "No limite da APA, indústrias e criatórios de animais devem } \\
\text { tratar seus esgotos antes de lança-los nos rios?" }\end{array}$ & - & 10,814 & 0,431 \\
\hline Zona x "No limite da APA é permitido utilizar defensivos químicos sem controle?" & - & 0,133 & 0,925 \\
\hline $\begin{array}{l}\text { Fonte de renda x "No limite da APA é permitido utilizar defensivos químicos sem } \\
\text { controle?" }\end{array}$ & - & 4,031 & 0,793 \\
\hline $\begin{array}{l}\text { Fonte de renda x "Na área da APA deve proibir ou limitar a extração de pedras } \\
\text { que causem erosão ou assoreamento nos rios da região?" }\end{array}$ & - & 7,329 & 0,513 \\
\hline
\end{tabular}

Legenda: $X^{2}$ = símbolo do teste de Qui-quadrado; $G$ = símbolo do teste $G ; p=$ nível de significância do teste; valores em negrito $=$ valores significativos a um nível de significância de $95 \%$.

Conforme pode ser visto na Tabela 1, não houve relação significativa entre $\mathrm{o}$ grau de escolaridade dos entrevistados e o conhecimento sobre o que é a APA dos Pireneus $\left(\chi^{2}=3,205 ; p=\right.$ $0,668)$. Contrastando com o resultado encontrado no presente estudo, Magalhães et al. (2010) afirmam que quanto maior o nível de escolaridade maior é o nível de conscientização da importância da participação na gestão da unidade, mas que outros fatores influenciam nesta relação. Dessa forma, outros fatores tais como a baixa divulgação da APA dos Pirineus frente à comunidade podem ter contribuído para o pouco conhecimento dos entrevistados sobre os objetivos dessa unidade de conservação e sua importância. Também é importante ressaltar que um maior nível de formação não implica necessariamente em uma participação efetiva, ou seja, mesmo que as pessoas possuam o conhecimento da importância das questões ambientais, elas podem não querer se envolver com essas questões.

A relação entre a participação das pessoas em grupos organizados vinculados ao meio ambiente e o conhecimento sobre o que é a APA dos Pireneus resultou em uma relação significativa $\left(\chi^{2}=8,954 ; p=0,006\right.$; Tabela 1$)$ demonstrando que quem participa de grupos organizados que prestam atividades vinculadas ao meio ambiente tem maior conhecimento sobre a existência desta unidade de conservação.

\section{Segundo Shuvartz}

(2006), frequentemente em parceria ou na posição de mediadoras, as ONG's influenciam na incorporação ou manutenção de atitudes ambientais positivas no movimento pela conservação. A atuação de ONG's no Município de Pirenópolis pode ter colaborado para a divulgação da APA dos Pireneus, mas além de informar que esta unidade existe, as ONG's deverão incorporar os corretos objetivos da unidade.

Em relação à análise da percepção dos entrevistados a respeito da função da APA dos Pireneus, o grau de escolaridade não influenciou nas respostas ( $G=25,654 p=0,200$; Tabela 1$)$, reafirmando a falta de relação entre a percepção dos entrevistados sobre existência da unidade de conservação e o grau de escolaridade. Dessa forma, pode-se inferir que, independentemente da escolaridade, outros fatores influenciam o conhecimento das pessoas sobre a existência da APA dos Pireneus e sobre as suas funcionalidades, e podem estar relacionados à baixa disseminação de informações sobre essa UC nas escolas do Município de Pirenópolis e em outras instituições de ensino formal e não formal.

Na relação entre a função da APA dos 
Pireneus com a participação das pessoas em grupos ambientais organizados, percebeu-se que não ocorreu relação significativa $(G=3,712$; $p=0,356$; Tabela 1). Observou-se que as duas únicas pessoas que definiram corretamente a função da APA dos Pireneus não pertenciam a grupos organizados vinculados ao meio ambiente, e proporcionalmente os entrevistados pertencentes a estes grupos erraram mais em suas definições, sendo que dos 22 participantes não pertencentes a grupos organizados que definiram para que serve a APA, cinco definiram errado. No entanto, 11 participantes vinculados a grupos organizados que definiram para que serve a unidade, cinco definiram de forma equivocada. Isto indica que, mesmo pela tendência das pessoas que participam de grupos organizados saberem mais da existência da APA, elas podem muitas vezes carecer de conhecimento a respeito dos objetivos da unidade de conservação, similar a quem não participa de organizações ambientais.

Na relação entre a área em que a pessoa morava (zona rural e urbana) e sua utilização de plantas e animais do Cerrado, obteve-se como resultado uma relação significativa $\left(\chi^{2}=5,825\right.$ $p=0,033$; Tabela 1 ) demonstrando que o fato de os entrevistados morarem na zona rural ou urbana influencia na utilização de espécies da biodiversidade nativa para a alimentação ou para a produção de medicamentos. No entanto, essa diferença significativa está relacionada muito mais ao número de pessoas que não utilizam nenhum produto da biodiversidade, pois tanto na zona rural quanto urbana o número de pessoas que relatou não utilizar animais ou plantas foi maior do que aquelas que relataram usar.

A mesma significância não foi obtida para a relação entre a idade dos entrevistados e o fato de utilizarem animais e plantas do Cerrado para alimentação e/ou para fins medicamentosos ( $G=7,754 ; p=0,2027$; Tabela 1). Refutou-se então a hipótese formulada de que maior utilização de plantas e animais do Cerrado ocorresse por parte das faixas etárias mais avançadas. Segundo Shuvartz (2006), ocorre uma perda de conhecimento do uso de plantas medicinais em detrimento da progressiva degradação do Cerrado, dificultando a coleta e a comercialização pelos raizeiros.

Em relação à criação da APA dos Pireneus para proteger os animais e plantas importantes ao bioma Cerrado, a relação com a zona de moradia dos entrevistados não foi significativa $(G=0,656$; $p=0.7374$; Tabela 1), ou seja, não há diferença na opinião dos moradores da zona rural e da zona urbana em relação ao papel da APA em conservar a biota. Moradores de ambas as zonas, em sua maioria (69 pessoas), declararam que a APA foi criada para proteger animais e plantas importantes ao bioma Cerrado, e apenas nove (9) pessoas divergiram dessa opinião.

Tanto quem participa de algum grupo organizado ligado às questões ambientais quanto quem não participa, alegou em sua maioria que a APA foi criada para proteger animais e plantas importantes ao bioma Cerrado (69 pessoas, sendo 54 não participantes de organizações ambientais e 13 participantes), demonstrando assim, que o fato de participar de tais grupos não alterou a opinião dos entrevistados em relação a este objetivo da APA dos Pireneus ( $G=0,065 ; p=0,969$; Tabela 1).

A relação entre a zona de moradia das pessoas entrevistadas e a opinião de proibir ou limitar a extração de plantas do Cerrado nos limites da APA não foi significativa ( $G=4,797 ; p=0,151$; Tabela 1), mas na tabela de frequência, verificouse que nenhum morador da zona rural respondeu 'não' a esta pergunta, enquanto 16 moradores da zona urbana responderam 'não' à proibição ou limitação da extração de plantas. Apenas 9 dos 18 moradores entrevistados da zona rural responderam esta questão, causando assim a omissão de $50 \%$ dos entrevistados nesta zona. Esta ocorrência evidencia a postura de liberdade exercida pelos moradores rurais em relação a extração de plantas.

Quando relacionada às categorias de idade com a pergunta sobre proibição ou limitação da extração indiscriminada das plantas importantes ao bioma Cerrado, verificou-se uma relação significativa ( $G=16,803$; $p=0.011$; Tabela 1), demonstrando a postura mais 
conservacionista das idades mais avançadas uma vez que a partir da faixa etária de 46 anos nenhuma pessoa respondeu que não deveria ser proibida ou limitada a extração de plantas. No campo explicativo desta questão, ou seja, quando questionadas por que deveria ocorrer a proibição ou limitação da extração de plantas, as respostas sugeriram que deveria haver a extração mediante controle.

Em relação à questão sobre a proibição ou limitação, dentro dos limites da APA dos Pireneus, a caça aos animais silvestres, tanto a relação com a zona de moradia e a idade dos entrevistados não foram significativas $(G=0,087 ; p=0,727$ e $G=$ 4,750; $p=0,595$, respectivamente; Tabela 1). Em ambos os casos, 73 pessoas responderam que se deve proibir e/ou limitar a caça aos animais silvestres, enquanto seis (6) disseram 'não', mas não justificaram esta opção e 21 não responderam, por não conhecerem a APA e não declararem nada a respeito. Estes resultados demonstram que em relação à caça aos animais silvestres, a maioria das pessoas entrevistadas demonstrou uma percepção ambientalmente consciente. Isto pode ser decorrente da divulgação em nível nacional e global sobre a conservação dos animais silvestres e das severas punições oriundas da Lei de Crimes Ambientais (Lei 9.605/98). Como alguns animais em extinção na região permanecem neste mesmo estado de ameaça em outras regiões de mesma fitofisionomia, ocorre uma divulgação difusa (em vários pontos) capaz de trazer mais rápido a conscientização almejada.

Tanto a zona de moradia quanto a idade dos entrevistados não configuraram uma relação significativa com o número de espécies em extinção conhecidas pelas pessoas ( $G=30,397$; $p=0,488$ e $G=14,916 ; p=0,828$, respectivamente; Tabela 1). Em ambos os casos, a grande maioria das pessoas não souberam descrever nenhuma espécie (81 pessoas), demonstrando que as pessoas necessitam de informações sobre as espécies ameaçadas de extinção na região.

Sobre o papel da APA dos Pireneus em manter a qualidade da água na região, não ocorreu relação significativa entre esta pergunta e a zona de moradia dos entrevistados ( $G=2,395 ; p=0,506$; Tabela 1), demonstrando uma valoração semelhante entre os moradores das duas zonas perante o papel da APA em proteger e manter a qualidade da água da região. Das 100 pessoas entrevistadas, 68 pessoas responderam que a APA dos Pireneus mantém esta qualidade, 24 não declararam nada devido a falta de conhecimento e 8 responderam que a APA não mantém tal qualidade, devido à falta de manejo e funcionamento.

Quando questionado aos entrevistados se as indústrias e criatórios de animais inseridos na área da APA dos Pireneus deveriam tratar seus esgotos antes de lançá-los nos rios da região, não ocorreu relação significante entre as respostas dessa pergunta com a zona de moradia das pessoas ou com a fonte de renda delas ( $G=1,015 ; p=0,958$ e $\mathrm{G}=10,814 ; \mathrm{p}=0,431$ respectivamente; Tabela 1). Dos 100 entrevistados, 70 responderam que os esgotos deveriam ser tratados, 25 não declararam nada e cinco (5) responderam que não deveriam ser tratados, mas não declararam o porquê deste apontamento. Observou-se na região que não há um alto número de indústrias, o que influencia na carência de informações e na falta de cobrança municipal sobre o gerenciamento de efluentes industriais. Entretanto, a criação de animais (bovinos, suínos e aves) exercida na região e os pequenos empreendimentos capazes de gerar efluentes nocivos (consultórios, oficinas, pequenas indústrias) são alvos importantes de conscientização ambiental e adequação de lançamentos de efluentes.

Em relação ao uso indiscriminado de defensivos químicos nas plantações inseridas dentro da APA dos Pireneus, não se obteve relação significativa entre esta variável e a zona de moradia e fonte de renda dos entrevistados ( $G=0,133$; $p=0,925$ e $G=4,031 ; p=0,793$; Tabela 1), rejeitando-se a hipótese de que o uso de defensivos químicos estaria intimamente ligado à fonte de renda provinda da agricultura e ao fato das pessoas residirem na zona rural. Esta relação não significativa pode ter ocorrido devido ao número reduzido de questionários aplicados a 
agricultores $(n=4)$.

Quando se questionou aos entrevistados

se deveriam ser limitadas ou proibidas as atividades de extração de pedras que causassem erosão ou assoreamento nos rios inseridos na APA dos Pireneus, não foi verificada relação significativa com a fonte de renda das pessoas $(G=7,329 ; p=$ 0,513; Tabela 1). Dos 100 entrevistados, 61 pessoas alegaram que deveria haver um controle (limitar), 11 alegaram que não deveria haver esse controle e 28 não declararam nada. Este elevado número de omissões, juntamente com o número de "nãos", revelou o conflito socioeconômico vivido por muitos trabalhadores das pedreiras no Município de Pirenópolis, pois alguns deles alegaram no campo dissertativo desta questão ("por quê?"), que esta atividade econômica desempenha um papel marcante no sustento de muitas famílias do município, fazendo com que muitos trabalhadores percam a possibilidade de questionar sobre a atuação ambiental das pedreiras. Laschefski e Costa (2008), em seu estudo, também evidenciaram que os movimentos ecológicos compostos por moradores da região também percebem os impactos das atividades das mineradoras como ameaças à qualidade da vida.

Diante de um processo de exploração de bauxita no entorno do Parque Estadual da Serra do Brigadeiro, Castro (2007) identifica a atividade mineradora como causadora de impactos de alto nível de criticidade, podendo esta atividade afetar direta e indiretamente o uso público da unidade, resultando na alteração da dinâmica do ecossistema local, causando a morte de espécies da vegetação e da fauna, e a degradação da paisagem. Sendo Pirenópolis, um município com forte atividade mineradora, a APA pode vir a sofrer os malefícios acima citados, gerando além da degradação ambiental, a piora da qualidade de vida dos moradores.

Quando questionados sobre as possíveis melhorias que a criação da APA dos Pirineus trouxe para a região, na zona urbana a melhoria mais declarada pelos entrevistados foi de proteção aos animais e plantas $(n=42)$, sendo que a segunda melhoria escolhida foi para a qualidade dos rios $(n=33)$. Já na zona rural, obteve-se o mesmo número de escolhas para as melhorias de proteção aos animais e plantas e da qualidade dos rios $(n=7)$.

Na zona urbana, o número de respostas apresentou representatividade na melhoria trazida ao ecoturismo $(n=27)$, mas este fato não foi verificado na zona rural. Isto se justifica pelo atrelamento existente entre algumas pessoas residentes na área urbana com o ecoturismo, o que repercute no meio rural de modo ínfimo. No geral, cinco pessoas declararam que a APA dos Pireneus não trouxe melhorias, marcando a opção "nada" ( $n=1$, zona rural e $n=4$, zona urbana).

Por fim, no levantamento das respostas dos entrevistados a respeito das ações que poderiam ser desenvolvidas na APA dos Pireneus, contribuindo para a geração de empregos em harmonia com a conservação ambiental da região observou-se novamente o vínculo maior dos entrevistados residentes na área urbana com o ecoturismo, enquanto no ambiente rural o maior número de respostas esteve relacionado ao plantio doméstico de plantas medicinais. Na zona rural, atividades como o ecoturismo, o artesanato com pedras, o artesanato com plantas e a produção caseira de alimentos do Cerrado obtiveram a mesma importância, como apresentada na Figura 2.

Segundo Vreugdenhil (2004), os financiamentos para biodiversidade são atualmente dirigidos principalmente para objetivos sociais e econômicos, que não são necessariamente para evitar extinções ou proteger paisagens únicas e biologicamente diversas. Atreladas a esta tendência mundial, as atividades mais escolhidas pelos entrevistados (ecoturismo, plantio doméstico de plantas medicinais, artesanatos e produção caseira de alimentos do Cerrado), vinculam recursos naturais com o desenvolvimento socioeconômico capaz de melhorar significativamente as condições de vida de pessoas pertencentes à classe baixa.

Aliando os atrativos turísticos inseridos na Área de Proteção Ambiental dos Pireneus, com o interesse da população em desenvolver o setor ecoturístico da região, é interessante haver a 


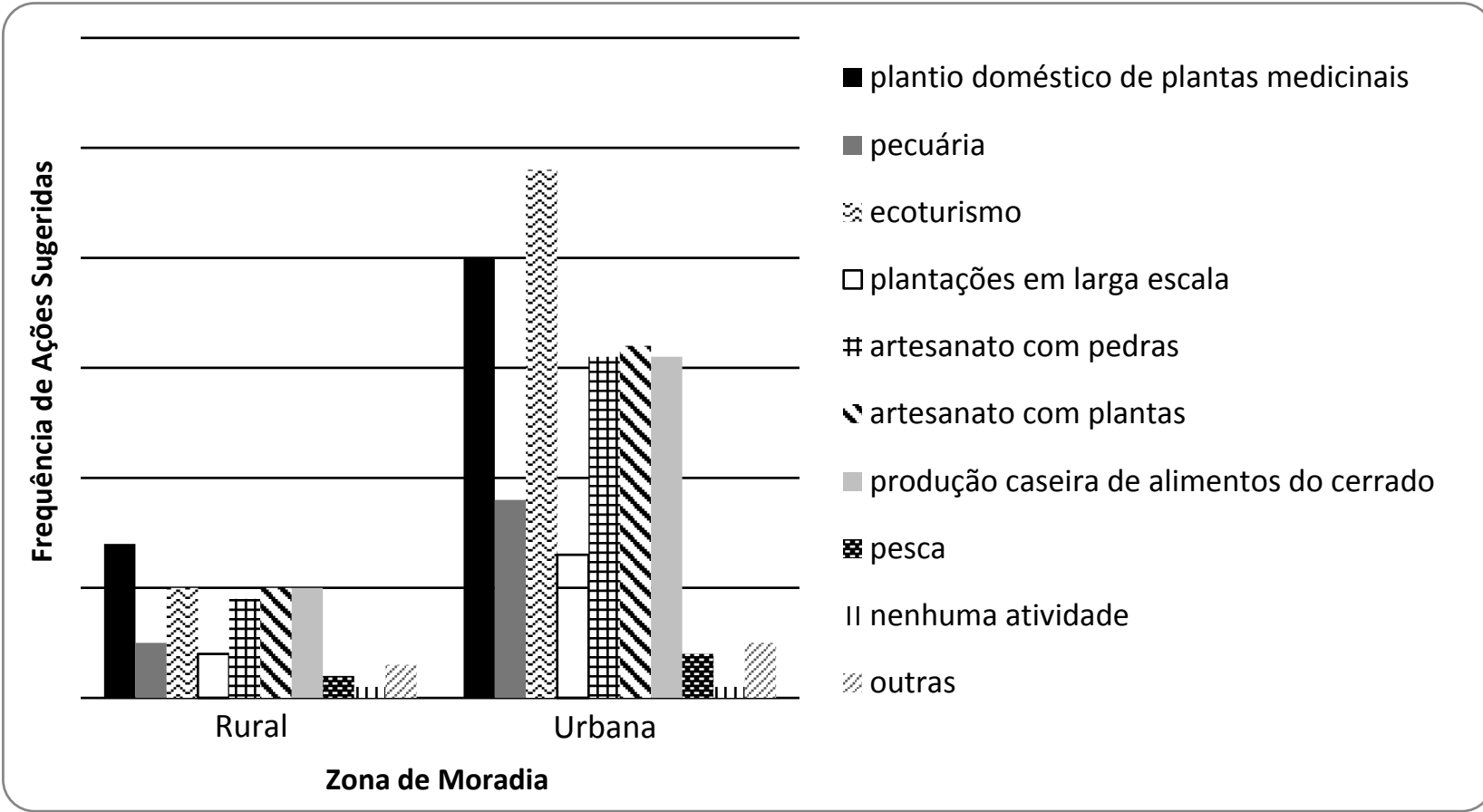

FIGURA 2: Frequências das atividades sugeridas pelos entrevistados da Zona Rural e da Zona Urbana do Município de Pirenópolis, capazes de serem desenvolvidas na APA dos Pireneus, gerando renda para a população e mantendo a proteção ao meio ambiente da região.

capacitação adequada dos interessados juntamente com o planejamento em harmonia com as funcionalidades da APA (Decreto № 5.174, de 17 de Fevereiro de 2000), para que o desenvolvimento sustentável deste setor aconteça efetivamente.

\section{CONCLUSÕES}

Por meio dos resultados apresentados ficaram evidentes os problemas no funcionamento da Área de Proteção Ambiental dos Pireneus relacionados à questão conceitual que a população possui, atrelada à falta de informação e de divulgação da unidade e dos conhecimentos acerca dos recursos hídricos e da biodiversidade da região. Em termos econômicos, notou-se importante o conflito socioeconômico e ambiental causado pela atividade de mineração no Município de Pirenópolis, e não obstante, a necessidade em disciplinar e acompanhar o ecoturismo e outras práticas sustentáveis na área desta UC.

Para um maior entendimento por parte da população residente na APA dos Pirineus sobre as suas funções e sua importância para a região, uma estratégia válida seria a maior divulgação dessa unidade de conservação junto à comunidade pelo Poder Público Municipal e o Órgão Gestor da UC (Secretaria de Meio Ambiente, Recursos Hídricos, Infraestrutura, Cidades e Assuntos Metropolitanos - SECIMA). Esta tarefa pode ser alcançada através de campanhas de divulgação da APA utilizando as emissoras de rádio e de TV local, do fornecimento de materiais impressos, como banners e cartilhas, nas escolas e eventos do município.

Tanto a rede pública quanto a privada de ensino, poderiam implementar nas escolas atividades de Educação Ambiental que visem inserir valores e conceitos ambientais e busquem promover as melhores instruções socioambientais e econômicas à população. Podendo ser realizadas atividades relacionadas aos animais ameaçados de extinção da região, ao cultivo e benefícios de plantas do Cerrado, à importância na proteção e no uso adequado da água e a importância do saneamento básico para a saúde pública do município.

As recomendações elencadas visam a participação conjunta da Prefeitura Municipal, do órgão ambiental estadual (SECIMA), dos grupos 
organizados vinculados ao meio ambiente (ONG's e Associações), e da população em geral, na busca pela melhoria da qualidade de vida garantindo a proteção ambiental proposta pelos objetivos estabelecidos para a Área de Proteção Ambiental dos Pireneus, na legislação de sua criação.

\section{REFERÊNCIAS BIBLIOGRÁFICAS}

BRASIL. Lei no 9.605 de 12 de Fevereiro de 1998 publicada no Diário Oficial da União em de 13 de Fevereiro de 1998.

BRASIL. Lei no 9.885 de 18 de Julho de 2000 publicada no Diário Oficial da União em 19 de Julho de 2000.

CASTRO, R. Avaliação da efetividade de gestão e do uso público no Parque Estadual da Serra do Brigadeiro MG. Dissertação (Pós-Graduação em Ciência Florestal) UFV, Viçosa - MG, 2007, 141 p.

IBGE. CENSO 2010. IBGE Cidades. 2010. Disponível em IBGE Cidades: <http://cod.ibge.gov.br/CU4>. Acesso em: 15 abr. 2014.

LASCHEFSKI, K. et al. Segregação social como externalização de conflitos ambientais: a elitização do meio ambiente na APA-Sul, Região Metropolitana de Belo Horizonte. Ambiente \& Sociedade, Campinas, Vol. $X I$, n. 2, 2008, 307-322 p.

MAGALHÃES, H. et al. Participação da sociedade civil na gestão de unidades de conservação e seus efeitos na melhoria da qualidade ambiental da região Sudeste do Estado do Mato Grosso do Sul. Acta Scientarum Human and Social Sciences, Maringá, Vol. 32, n.2, 2010, 183-192 p.

MMA. Livro Vermelho da Fauna Brasileira Ameaçada de Extinção. Ministério do Meio Ambiente. Disponível em:<http://www.mma.gov.br/estruturas/sbf2008_dcbi o/_publicacao/147_publicacao31032009031646.pdf>. Acesso em: 16 abr. 2014.

OLIVEIRA, F. T. Ecoturismo, Gestão Participativa e Dilemas Locais: Uma Análise na APA do Puraquequara. Revista Iberoamericana de Turismo - RITUR, Penedo, Vol. 1, n. 1, 2011, 10-22 p.

PALMA, I. R. Análise da percepção ambiental como instrumento ao planejamento da educação ambiental. Dissertação (Mestrado em Engenharia) - Escola de Engenharia, Universidade do Rio Grande do Sul. Porto Alegre, 2005, 83 p.
SEMARH. Unidades de Conservação. 2014. Disponível em: <http://www.semarh.goias.gov.br/site/unidadesde-conservacao>. Acesso: 16 abr. 2014.

SHUVARTZ, M. Representações sociais de biodiversidade na região do Parque Nacional das Emas - GO. Tese (Doutorado em Ciências Ambientais) - PróReitoria de Pesquisa e Pós-Graduação, Universidade Federal de Goiás, Goiânia, 2006, 106 p.

VREUGDENHIL, D. Gerenciamento de áreas protegidas: necessidades de biodiversidade e integração socioeconômica. Revista Natureza \& Conservação, Vol. 2, n. 1, 2004, 12-17 p. 